\title{
ЛЕКСИКА ПИСЬМЕННЫХ ТЕКСТОВ КАК СОКРОВИЩНИЦА КУЛЬТУРЫ НОСИТЕЛЕЙ ЯЗЫКА И ИСТОЧНИК ЕЕ ПОВЫШЕНИЯ
}

\author{
VOCABULARY IN WRITTEN TEXTS AS A SOURCE OF KNOWLEDGE \\ ABOUT NATIVE SPEAKERS' CULTURE AND THE BASIS \\ FOR DEVELOPING THIS CULTURE
}

\author{
НАТАЛИЯ МАТВЕЕВА
}

\begin{abstract}
The article focuses on the origin of and studies obligatory written texts which are regarded as a source of knowledge about the culture of native speakers of ancient Indian, ancient Chinese, classic Greek and Latin as well as Arabic and eastern Slavic languages.

Much attention is paid to the theory of "correctness" as regards the necessity for native speakers to improve their cultural and linguistic literacy.

This article shows the necessity of identifying a specific field within lexicology, i.e. "glossology", which focuses on analyzing semantically difficult lexis (obsolete words, terms, neologisms, etc.) in obligatory written texts.

As a result of a theoretical study of such lexemes, a special field within lexicography, i.e. "glossography", was identified; this field deals with studying and developing the theoretical and practical basis for creating dictionaries of lexical-semantic difficulties in written texts.
\end{abstract}

Наталия Матвеева, Черноморский государственный университет им. Петра Могилы, Николаев - Украина.

„В книжных словах находим мудрость...”. Так писал Нестор-летописец в Повести временных лет под 1037 г., высоко оценивая тот культурологический и воспитательный потенциал, который содержится в языке вообще и в слове в частности. Откуда взялась бы у книг их „великая мудрость", если бы не необычайная емкость, многогранность слова, а точнее, смысла, заключенного в нем?

Мир познается через язык, благодаря языку, сущность которого состоит не только в передаче мысли от человека к человеку, но и в функции быть носителем и хранителем мысли, всего знания в индивидуальном и коллективном сознании человека. Собственно возникновение и самой культуры народа связано с появлением языка как средства отражения объективного мира в сознании человека, поэтому познание культуры начинается, прежде всего, с познания слова, ведь в любом письменном тексте, в любом литературном произведении нет ничего, 
что выражалось бы без его помощи. Общепризнанно, что филология как совокупность гуманитарных наук, изучающих культуру народа, выраженную в языке и литературном творчестве, возникла в результате изучения текстов. Сначала создание первых письменных памятников, а затем и книгопечатание были поворотными этапами в истории культур всех народов, поскольку давали в руки человеку письменный текст как определенным образом закодированную информацию и возможность передавать ее таким образом последующим поколениям. Именно текст и был той реальностью, которая органически объединяла не только разные аспекты языка, но, по существу, и смежные науки: языкознание, литературоведение и историю, направленные на один и тот же объект. Необходимость углубленного изучения текстов в разных аспектах привела к постепенной дифференциации лингвистических, литературоведческих, исторических и других дисциплин.

В соответствии с законом диалектического отрицания древняя филология как единая наука „при тексте” уступает место аналитическому „поуровневому” изучению объекта, чтобы потом возродиться на новом этапе развития как синтез знаний о языке, литературе и культуре народа в их взаимосвязи и историческом развитии. Обращение к тексту, к синтезу языковых единиц разных уровней способствует осознанию единства филологии на современном этапе развития языкознания и смежных с ним дисциплин.

Сосредоточившись на тексте, создавая к нему служебный „комментарий” (наиболее древняя форма и классический прототип филологического труда), филология под этим углом зрения вбирает в свой кругозор всю ширину и глубину человеческого бытия, прежде всего, бытия духовного (Аверинцев, 1979: 372-373).

Существует мнение, что становление собственно науки о языке следует относить к началу XIX века, когда появилось сравнительно-историческое языкознание, весь предшествующий период называют иногда „донаучным" (Звегинцев, 1960: 51). Это справедливо лишь отчасти, поскольку многие языковые и в частности теоретические лексикологические и лексикографические положения восходят к глубокой древности. Традиции древнего языкознания подразделяют обычно на древнеиндийскую, древнекитайскую, классическую греко-латинскую и арабскую.

Основные аспекты конфуцианской философии, в которой нашла отражение и теория „правильности слова”, являлись общими и для древнеиндийского, и для греческого миропонимания. Так, например, краткая формула теории наименований, созданная Конфуцием, звучит так:

Если имя дано неверно, то речь не повинуется, если речь не повинуется, то дело не может быть образовано. Если же имя дано верно, то и речь повинуется, если речь повинуется, то и дело образуется (Собрание классиков, 1935: 283). 
Согласно этой философии слова́ „имя" и „речь” не должны были произноситься произвольно, так как вслед за их звучанием всегда проистекало действие, относящееся как к людям, так и к вещам. Словесная магия, свойственная мифологическому мышлению, наделяла эти слова постоянным действенным началом. (Ср. начальные строки в Еъангелии om Иоанна: „В начале было Слово, и Слово было у Бога, и Слово было Бог"), где Слово - основа становления мира как целого.

Таким образом, слово в философии древних народов понималось как начало начал, дающее разумное содержание всему и в качестве мирового разума (Логоса), и как разумность отдельного человека. Разумность человека, идущая от слова, в котором заключено понимание мира и объяснение этого мира человеку, дает возможность приобретения знаний, необходимых для быта, хозяйства, земледелия, астрологии, морали, этики и т.Д. (Амирова, 1975: 34).

Слово, будучи всеобъемлющим началом, требовало к себе особо бережного отношения. Слово нужно было п р а в и л ь н о создавать и применять, иначе нарушится порядок в обществе (Собрание классикob, 1935).

Правильно понимать следовало, прежде всего, тексты сакральных книг. У древних индийцев это Веды - сборник священных гимнов, священное знание о Вселенной, которое бог Брахма, по преданию, дал людям. На основе этих знаний и доныне в значительной степени базируются правовые, имущественные и этические нормы поведения индийцев.

В соответствии с конфуцианской философией, брахман не должен произносить „неправильные” слова. Человек, употребляющий слова в правильном значении, тонко различая все лексические оттенки, всегда побеждает в окружающей действительности.

Древнеиндийская наука о языке в значительной степени повлияла на древнегреческую лингвистическую традицию. Однако если древнеиндийское языкознание имело в общих чертах эмпирический характер, то теория языка в Древней Греции была одной из составных частей философии. Одной из наиболее важных проблем, которыми занимались в античные времена на протяжении нескольких столетий, являлась проблема соотношения между вещами и словами - их именами. Суть этой проблемы сводилась к ответу на вопрос: соотносятся слова с природой вещей, или связь между словом и вещью устанавливается произвольно, и вследствие этого - „неправильно”. В дискуссии, занимая разные позиции, приняли участие Гераклит, Демокрит, Протагор, Эпикур и др. Вопросу „правильности слова” посвящен и диалог Платона Кратил. В этом уникальном произведении не только рассматривается правильность имен как необходимое условие для достижения 
всеобщего порядка, но и описываются методы создания правильных имен, то есть названий, и это сделано посредством объективного анализа самого процесса наименования.

Древнеиндийское и античное греко-римское языкознание оказали определенное влияние и на арабскую науку о языке, расцвет которой приходится на эпоху Халифата (VI-VII вв.). Интерес к лингвистике здесь также стимулировался чисто практическими потребностями - сделать понятной и доступной для мусульман священную книгу Коран и уберечь классический арабский язык от влияния диалектов.

Средневековье знаменовало собой то, чего не знали предшествующие века - появление мировых религий. Н.И. Конрад писал по этому поводу: „Это были: буддизм в Восточной, Центральной и отчасти Средней Азии, ислам в Средней и Передней Азии и в Северной Африке, христианство в Европе и отчасти в Передней и Средней Азии. Конечно, буддизм и христианство зародились и получили свое развитие еще в древнем мире, но только в период Средневековья они превратились в религии мирового масштаба. Ислам возник в Средние века, но также быстро приобрел мировое значение" (Конрад, 1966: 103).

Каждая из этих религий создала свою концепцию жизни и поведения: мораль, философию, право, этику и эстетику, которые закреплялись в канонических текстах на соответствующих языках: это Библия, Коран, конфуцианские произведения, индийские Веды. Характерно, что эти тексты создавали основу всей системы знаний и идеологический фундамент общества. Особое внимание уделялось правильному пониманию и использованию Слова, потому что Слово, по мнению древних философов, было „орудием создания культуры”, а главным достоянием человека в древнем мире считалось знание. Знание канонического языка, понимание канонических текстов было присуще лишь образованному и культурному человеку, и соответственно ставило этого человека в привилегированное положение.

C XI века усиливается интерес к письменным текстам у восточных славян. Толчком для этого послужило принятие христианства в Киевской Руси в 988 году. Если учесть, что именно церковные книги, в первую очередь библейские, особенно ЕВангелие и Псалтырь, бытовали в Киевском государстве с самой глубокой древности, что и в дальнейшем их копировали в большем числе и тщательней, чем другие тексты, что книги эти не только чаще читали, но и заучивали наизусть, то станет понятным, какую огромную роль играли они в жизни и культуре Древней Руси и в последующие времена. До XVII ст., по крайней мере, образованность человека у восточных славян определялась уровнем правильного понимания Слова в сакральных текстах и вообще знанием Святого Письма и Патристики. Поэтому можно отметить, что наблюдение над лексическим составом облигаторных письменных тек- 
стов и у восточных славян явилось одним из древнейших направлений в языкознании.

Практические соображения заставляли читателей облигаторных письменных текстов заменять то или иное малоизвестное слово другим, лучше знакомым, или же в текст одного языка вносить надстрочные пояснения отдельных слов на другом языке. Очень рано стали появляться глоссы между строк. Подбирали менее знакомые слова для объяснения их значения другими выражениями в виде коротеньких словарей, глоссариев (Ягич, 1910: 11). Одной из главных причин появления глоссы при слове, безусловно, являлась его малопонятность и неусвоенность языком в прошлом.

Вместе с тем и в наше время давняя лингвистическая концепция, требующая понятности и „правильности” слова, не утратила своей актуальности. Ведь нередко тот, кто пишет, исходит из того, что имена, события, местности, о которых идет речь, - известны тем, кто читает. Чаще всего коммуникации не происходит именно по причине недопонимания между теми, кто пишет и читает, так как используются непонятные для воспринимающей стороны понятия, а точнее, их названия. Об одном из случаев такого „недопонимания” в практике известного адвоката Ф.М. Плевако ярко рассказал В.В. Виноградов в статье Основные типы лексических значении слова (Виноградов, 1953: 25). Роль адекватности знаний при передаче и восприятии означаемого подчеркивает Р.А. Будагов:

Хотя всем словам, словосочетаниям и синтаксическим конструкциям всегда что-то соответствует в мысли, далеко не все содержание мысли непосредственно выражается в словах, словосочетаниях и синтаксических конструкциях. Поэтому возникает все еще почти не изученная проблема: как следует п о н и м а т ь степень передачи означаемого с помощью означающего, и каковы границы „полноты” подобной передачи (Будагов, 1967: 12).

Общеизвестно, что лексика представляет собой наиболее сложную и вместе с тем наименее изученную систему. Сложность лексической системы языка заключается в том, что словарный состав не только практически безграничен, но и не очерчен в каждый момент существования языка с достаточной определенностью. Как отмечает Д.Н. Шмелев,

тогда как в отношении тех или иных фонем и грамматических форм мы всегда с полной категоричностью можем сказать, существуют они в языке или нет, относительно слов и значений слов это иногда не так легко сделать. Например, [...] входят ли в словарный состав современного русского языка такие слова, как ланиты, втуне, вельми и под.? Или такие, как кейф, кейфоbams [ср. у Достоевского: „...бульдог расположился среди комнаты и лениво наслаждался своим послеобеденным кейфом"]. Фрыитик... бомонд... бонмо и т.д. Или дансинг, сомбреро, вигъам (Шмелев, 1964: 6). 
Что же это за слова, и действительно ли они входят в состав современного русского языка, и если входят, то почему, на каких условиях? Думается, решить проблему функционирования в современном языке семантически затемненных, „трудных" слов (устаревших, диалектных, терминов, неологизмов и т.д.) можно посредством введения понятия г л о с с о л о г ия.

Под глоссологией понимаем раздел лексикологии, посвященный изучению типологии лексико-семантических трудностей словарного состава современного литературного языка в его письменной разновидности, анализу источников порождения семантически „трудных" слов, а также их комплексной интерпретации.

Для дефиниции языковой области, вычленяемой в пределах лексики, содержащей лексико-семантические трудности письменного текста и являющейся объектом семасиологических и ономасиологических исследований, целесообразно, на наш взгляд, использование термина г л о с с о н и м и я. Лексическая единица (как слово, так и фразеологизм), функционирующая в облигаторных, социально значимых текстах, содержащая лексико-семантическую трудность и имеющая ценностное культурологическое значение, может быть названа г л о с с е м о й.

Одной из основных категорий глоссологии является категория лексико-семантической трудности (ЛСТ). Сам термин языковая „трудность" в языкознании, в частности лексикографии, уже общепринят. Ср. названия словарей: Словарь трудностей русского языка (Розенталь, Теленкова, 1987); Краткий словарь трудностей русского языка (1968) и др.

Термин „лексическая", а также „лексико-семантическая трудность" в лексикографии впервые введен авторами Словаря лексических трудностей художественной литературы (Макаров, Матвеева. См. издание: Киев 1989 и дальнейшие переиздания: Москва 1993; Москва 1998), а в дальнейшем разработан в ряде научных работ (см. Матвеева, 1997; 2009).

Понятие ЛСТ, хотя и не вычленяемое ранее в особую категорию, в языке существовало издавна. По сути, категория ЛСТ - это именно те глоссы, которые традиционно выделялись еще в сакральных памятниках письменности практически всех народов, и в частности в древнерусской письменности.

Слово глосса, производимое от греческого, означает не только язык, но употреблялось грамматиками для обозначения примечания, прилагаемого к неизвестному слову или фразе, с целью их пояснения. Творения, содержащие такие примечания, назывались глоссариями и заключали в себе не только филологию, но и вообще сведения по разным наукам, - медицине, географии и прочее, а также из Св. книг Библии. Примечания на последнюю назывались священными глоссами. Библии были предметом экзегетических исследований; и слово глоссы, которое у греков обозначало подлежащие истолкованию сло- 
ва, употреблялось у латинян вместо „самого объяснения” (Православная богословская энциклопедия, 1903: 410-411).

Многозначность в речи и как следствие этого - „недопонимание” - обусловлена не только внутриязыковыми причинами (перенос имен с одного предмета на другой, в чем-то близкий первому), но и внеязыковыми факторами, в частности спецификой и многомерностью того возможного мира, по отношению к которому язык употребляется как знаковая система. Поэтому важным аспектом глоссологии является изучение слов в их отношении к действительности, поскольку именно в словах, в их значениях самым непосредственным образом закрепляется жизненный опыт коллектива в определенную эпоху.

Глоссонимия как система, включающая ЛСТ письменного текста, связана со всей совокупностью книжных функциональных стилей языка, хотя по степени представленности в них глоссем эти стили заметно различаются. Наши наблюдения показали, что наиболее широко представлены глоссемы в стиле художественной литературы и публицистике, наименее - в официально-деловом стиле.

Поскольку лексический состав языка неоднороден, стратифицирован, это тоже нашло отражение в глоссологии. В ней выделяются категории лексических единиц по разным основаниям: 1) по сфере употребления - лексика общеупотребительная и локализованная; 2) по исторической перспективе - неологизмы, архаизмы, историзмы; 3) по происхождению слов или обозначаемых ими реалий - заимствования, экзотизмы, варваризмы; 4) по отношению к языковой системе и функционированию - активная и пассивная лексика, окказионализмы.

В пределах глоссологии можно выделить общую, частную, историческую, сопоставительную и прикладную области. Общая глоссология устанавливает общие закономерности выявления, функционирования глоссем в различных языках, частная - исследует ЛСТ одного языка. Историческая глоссология дает описание динамики данного словарного состава либо статическое описание среза исторического состояния языка в данной области. Сопоставительная глоссология исследует ЛСТ с целью выявления их общности и различия в отдельных языках, а также с целью выявления общих семантических закономерностей. Как часть лексикологии прикладная глоссология также охватывает преимущественно четыре сферы: лексикографию, лингводидактику, культуру речи и перевод.

Можно отметить, что для глоссологии особенно важны две базовые функции языка: коммуникативная как средство передачи информации от одного участника акта коммуникации другому и когнитивная - мыслеобразующая, познавательная функция. Поскольку глоссология соотносительна с когнитивной семантикой в области правильного понима- 
ния семантически затемненных, но культурологически ценностных лексических единиц, на наш взгляд, наряду с когнитивной целесообразно выделить соотносящуюся с ней глоссемную функцию (распознаВания и осмысления семантически неясного или затемненного), включающую, в свою очередь, кумулятивную - накопительную функцию, выражающуюся в способности языка отражать, фиксировать и сохранять информацию о постигнутой человеком действительности, а также образовательно-воспитательную, директивную функцию. Взаимодействуя и переплетаясь, все эти функции характеризуют глоссологию как лингвистическое понятие. Вместе с тем ведущей функцией для этой области языкознания является когнитивная. Еще В. Гумбольдт считал, что язык возникает не как внешнее средство общения людей в обществе, а как средство познания мира, как инструмент развития духовных сил и образования мировоззрения людей (Гумбольдт, 1984: 51). В этом высказывании ученого содержится и мысль о директивной функции языка - направляющей, воздействующей и формирующей личность. Л.В. Щерба в свое время также подчеркивал, что в содержательные планы слов непременно входят идеологические компоненты, обусловленные мировоззрением, характерным для данной этнокультурной общности (Щерба, 1974: 311). Следовательно, глоссологию с полным правом можно считать лингвокогнитивной, лингвокультурной и лингводидактической областями языкознания.

Мысль о воспитании личности путем приобщения к культурным ценностям человечества через язык прослеживалась на протяжении тысячелетий в традициях древнеиндийского, древнекитайского, классического греко-латинского и арабского языкознания, а также в последующие времена. В частности в XVII ст. распространение получила философско-лингвистическая концепция „пансофии” - всеобщей мудрости, образованности - Яна-Амоса Коменского, согласно которой необходимо создать науку о мироздании, универсальную классификацию предметов и явлений, которые следует знать всем. По мнению Коменского, распространение „пансофии” на все человечество привело бы к коренному его исправлению и положило бы начало созданию гармонического общества. При этом вся человеческая жизнь - с момента рождения и до самой смерти - должна стать постоянным совершенствованием знания: наука, культура, практическая деятельность, успеху которой служили естественнонаучные и исторические знания, являются только материалом для „упражнения" и средством самосовершенствования. В свою очередь, усвоение культуры, считал Гумбольдт, возможно прежде всего через родной язык (Гумбольдт, 1984).

Исключительное место среди мыслителей, признававших за языком как учебным предметом огромную воспитательно-образователь- 
ную роль, занимает К.Д. Ушинский. Для Ушинского „родное слово есть основа всякого умственного развития и сокровищница всех знаний: с него начинается всякое понимание, через него проходит и к нему возвращается" (Ушинский, 1948, т. 3: 166). Ушинский отмечал, что, усваивая родной язык, ребенок усваивает не одни только слова, их сложения и видоизменения, но и бесконечное множество понятий, воззрений на предметы, множество мыслей, чувств, художественных образов, логику и философию языка. Поэтому, являясь самой полной и правдивой летописью всей духовной, многовековой жизни народа, язык в то же время является и величайшим народным наставником, учившим народ даже тогда, когда не было еще ни книг, ни школ. Этот удивительный педагог - родной язык - не только учит многому, но и учит удивительно легко, по какому-то недосягаемо облегченному методу.

Огромное значение языку как неиссякаемому источнику информации о культуре народа (как материальной, так и духовной) придавал А.А. Потебня. Изучение языка, по его мнению, важно потому, что слово не только средство для выражения готовой мысли: оно - способ, прием ее создания и разработки. Язык - это сама мысль. Самое рождение мысли обнаруживает ее органическую связь с языком, зависимость от языка. В связи с этим чрезвычайно важно изучение мифов, преданий, отраженных в языке, так как они прочно объединяют людей, принадлежавших к одному народу, нации. Эта мысль многократно обосновывается А.А. Потебней в ряде работ (Потебня, 1976).

С обучением учащихся информации о культуре страны в лингводидактике связаны три направления: лингвострановедение, этнокультуроведение и культурная грамотность, зародившиеся почти в одно время и имеющие как общие, так и специфические черты, причем культурная грамотность - новое направление, не выделявшееся ранее в восточнославянской лингводидактике. Под культурной грамотностью понимаем аспект преподавания родного языка его носителям, в котором с целью познания обучаемыми как общечеловеческой, так и своей национальной культуры особое внимание уделяется кумулятивной функции языка. При этом методика преподавания культурной грамотности, так же, как и лингвострановедения, имеет филологическую природу - ознакомление с культурой проводится через посредство родного языка в процессе его изучения.

При обучении культурной (и языковой) грамотности, а также для адекватного усвоения облигаторных текстов необходимо создание серии учебных глоссариев с учетом возрастных особенностей адресата. Теоретическое обоснование создания серии глоссариев предусматривает выделение в сфере лексикографии специальной области - г л о с с о г р а ф и и, в пределах которой исследуются и разрабатываются 
теоретические и практические основы создания учебных словарей лексико-семантических трудностей письменного текста.

Традиции составления глоссариев", имеющих некоторые черты кониептографии, в разных формах в русской лексикографии продолжают развиваться и в наше время. Причем если до 90-х годов XX ст. это происходило спонтанно, с оглядкой на традиционно сложившееся разделение словарей на филологические и энциклопедические, то, начиная с середины 90-х годов, словарей, в которых сознательно совмещаются принципы одних и других, становится все больше. Безусловно, связано это с тем, что все большее распространение приобретает когнитивная лингвистика и концептология. Определенное влияние на создание словарей с комплексной интерпретацией слова оказал и выход в 1989 году Словаря лексических трудностей художественной литературы с его дальнейшими переизданиями (Киев-Москва) (см. Список литературы).

Все это позволяет считать, что наукой осознан уже определенный заказ, в соответствии с которым вырабатываются наиболее оптимальные способы презентации языкового материала в произведениях лексикографического типа. Социальный заказ выступает при этом важнейшим детерминирующим фактором содержания учебного словаря. Он определяет необходимые для каждого этапа развития общества качества личности, ее ценностные ориентации и систему оценок. Эти особенности социального заказа общества в значительной степени обусловливают отбор и систематизацию словника, структуру словаря и словарной статьи, характер иллюстративного материала и т.п.

Создание глоссариев окажется полезным для читателей: будет способствовать расширению их лингвистического и культуроведческого кругозора, воспитанию внимания и любви к слову, что рассматривается в лингводидактике как одно из важнейших психологических условий активизации спонтанного обогащения словарного запаса учащихся. Значительную роль такие словари могут сыграть и в формировании умений и навыков пользования справочной литературой в самостоятельной работе учащихся над письменным текстом, над повышением уровня речевой культуры.

Настало время создания универсального словаря культурной грамотности для носителей языка, в котором будут собраны лексемы (как отдельные слова, так и фразеологические единицы), представляющие значительную ценность из сферы национальной и общечеловеческой культуры, знать которые необходимо представителям любой национальности. Такие лексемы, без сомнения, должны рассматриваться как концепты и интерпретироваться комплексно.

\footnotetext{
* Термин глоссарий традиционно понимается как словарь с подробным описанием внеязыковой сферы обозначенной словом реалии.
} 


\section{Список литературы}

Аверинцев С.С., 1979, Филология, [в:] Русский язык: энцииклопедия, гл. ред. Ф.П. Филин, Москва.

Амирова Т.А., Ольховиков Б.А., Рождественский Ю.В., 1975, Очерки по истории иингвистики, Москва.

Будагов Р.А., 1967, Категория значения в общей теории языка, [в:] Проблемы языкознания: доклады и сообщения советских ученых на Х Международном конгрессе мингвистов, Москва.

Виноградов В.В., 1953, Основные типы лексических значений слова, „Вопросы языкознания", № 5.

Гумбольдт В. Фон., 1984, Избранные труды по языкознанию, Москва.

Звегинцев В.А., 1960, Теоретико-лингвистические предпосылки гипотезы Сепира-Уорфа, [в:] Новое в лингвистике, вып. 1, Москва.

Конрад Н.И., 1966, Запад и Восток, Москва.

Макаров В.И., Матвеева Н.П., 1989, Словарь лексических трудностей художественной литературы, Киев.

Макаров В.И., Матвеева Н.П., 1993, От Ромула до наших дней. Словарь лексических трудностей художественной литературы, Москва.

Макаров В.И., Матвеева Н.П., 1998, Русская художественная литература: лексические трудности, Москва.

Матвєєва Н.П., 1997, Лексико-семантичні труднощі писемного тексту та їх лексикографічна інтерпретація. Автореф. дис. ...Д-ра. филол. наук, Київ.

Матвеева Н.П., 2009, Глоссонимия русского и украинского языков и ее лексикографическая интерпретация (На материале облигаторных художественных текстов), Познань.

Потебня А.А., 1976, Эстетика и поэтика, Москва.

Православная богословская энииклопедия, 1903, Санкт-Петербург.

Собрание классиков (Чжу изы изичэн), 1935, т. 1, Шанхай.

Ушинский К.Д., 1948-1949, Собрание сочинений 8 6-ти томах, т. 3, Москва-Ленинград.

Шмелев Д.Н., 1964, Очерки по семасиологии русского языка, Москва.

Щерба Л.В., 1974, Языковая система и речевая деятельность, Ленинград.

Ягич И.В., 1910, История славянской филологии, Санкт-Петербург. 
